\title{
Analysis of Guangdong Energy Demand Forecast Based on DIP- REM Model
}

\author{
Yuan Zhang ${ }^{1, a}$ \\ ${ }^{1}$ Nanfang College of Sun Yat-sen Univeristy, Conghua, Guangzhou, Guangdong, China
}

\begin{abstract}
Computer data mining technology has a positive impact on the accurate prediction of China's energy demand. In order to effectively alleviate the energy crisis that China is currently facing, and further forecast the energy demand, it will provide an active driving force for the sustainable economic development of our country in the future. In this study, the authors studied the current energy use trends in China, and then the authors used the DIP-REM model to predict their future development needs based on a study of the use of energy resources in Guangdong Province. This model can accurately predict the future energy expansion value of Guangdong Province. The research aims to provide a reference for related research on China's energy demand forecast.
\end{abstract}

\section{Introducing}

Energy, as an important material in the development of today's era, has an important role in ensuring the economic development of the times and the stability of social development [1]. With the development of various industries in the world, the demand for energy is also increasing. In the actual energy application process, many energy materials are non-renewable, and energy use and waste are also responsible for a certain degree of global energy crisis[2]. Therefore, many countries and regions in the world have begun to seriously consider the use of energy, and thus aim to further predict the world's energy needs through the integration of current energy use and structural frameworks for economic development, and thus realize the entire world. The sustainable development of the economy provides a positive driving force [3]. For the prediction of energy supply and demand due to the large number of influencing factors involved, this also increases the predicted workload and credibility to a certain extent [4]. The development of computer technology provides a more systematic data analysis model for the development of various industries, and these data analysis models can make up for the deficiencies in the traditional data analysis process, and then consider a variety of influencing factors. The improvement of the accuracy of the final analysis results provides a positive impact [5]. In this study, the author will use the current status of energy use in Guangdong Province of China as the research object, and then the author uses the DIP-REM model to predict the energy demand in Guangdong Province of China. The research aims to provide the future economic development of China's Guangdong Province. Energy data security provide theoretical references for the sustainable development of China's overall economy and the use of energy.

\section{State of the art}

With the rapid development of the world, energy has always been the cornerstone of the development of various industries and maintains a steady increase [6]. Some scholars believe that in the development of a country or region, energy has no doubt about its impact, and the development of these areas can only be based on the premise of relying on its basic energy, and then the most efficient use of its energy can only be finalized. To achieve the sustainable development of the entire country and region [7]. However, in the current society of industrialization and urbanization, the use of energy between countries and regions has also increased, and the issue of energy supply has also become increasingly prominent [8]. For example, the "oil crisis" that has erupted in the modern era has, to a certain extent, stimulated energy-related research scholars in many countries to discuss and study issues such as energy structure and use in the current era [9]. However, due to the current exponential growth pattern of energy use with economic development, and the large amount of energy use has also had a negative impact on the current international environment, many countries have created international disputes or even wars due to energy use. 10]. Therefore, in the context of this era, many research scholars proposed that the issue of energy demand should be mentioned on the agenda, and that the prediction of energy demand problems be further realized through the construction of certain data analysis models, thus fundamentally Durable use and sustainability provide data support [11]. The

a email: zysysu@163.com 
development of computer technology has provided technical support for the construction of the world data analysis model, and a large number of data analysis models have also begun to be applied to the actual energy demand forecasting process, such as the grey correlation analysis model, DIP-REM model, etc. [12]. These data analysis models can be used in the actual analysis process can be a more complex analysis of a variety of factors, so that the original traditional model can not explain the different factors of different influences, so that the model results of the analysis accuracy Higher, it also provides data support for the economic growth of developed countries in the world [13].

\section{Methodology}

In the course of China's economic development, the demand and use of energy are increasing year by year. It can be said that the large-scale use of energy also provides a positive driving force for China's rapid economic growth. However, the large-scale use of energy has also caused problems such as the depletion of energy in our country. In this study, the author takes the development process of our country as an example, and reads relevant references and national statistical data. Based on the analysis of China's current development status and energy use, the research aims at the follow-up energy. The research on the necessity of prediction provides a reference basis and provides theoretical support for the study of China's energy use trends.

With the advent of the energy crisis, the country has also begun to realize the importance of energy forecasting analysis. Only through a detailed analysis of the trends in the use of energy, and the use of a more systematic analysis model to analyze the data and information of current energy use, and to predict and analyze the sustainability, use time, and effectiveness of subsequent energy sources, can we eventually become China. The long-term use of energy provides data and theoretical support [14]. However, in the traditional energy use analysis process in China, many scholars simply use a simple data analysis model to predict energy use. The use of these simple models may only analyze single factors and influence With the coexistence of factors, the use of these simple models is significantly reduced. And in the process of analyzing certain data, because the influences of different influencing factors may not be the same, the use of simple models will be treated equally, and may eventually cause the original impact of the analysis results. The higher factors are underestimated, while the lower impact factors are overestimated, which affects the final analysis accuracy. Therefore, under this trend, the construction and application of a more systematic data analysis model has become an important development direction for current Chinese scholars to predict energy use. The development of computer technology as an important technology in the development of today's era, the development of this technology can be for the collection of relatively large amounts of data information, and through the construction of the data analysis model of its system, and then for some of the massive The analysis of data factors provides a more credible analysis result, and finally provides a theoretical reference for solving some practical problems. Therefore, the more systematic and scientific data analysis model has been recognized by many researchers, and then it will be applied to the actual energy problems, such as the DIP-REM model. Because these models apply computer technology to them, they have the inclusiveness of massive data information. By using the high efficiency of computer technology, the results of data analysis also make the credibility of the data analysis more reliable, and thus the development process of certain industries in China. The use of energy in China provides basic data support. However, in the process of using these data models, due to the existence of some subjective and objective factors, the combination of theory and practice is still not enough, and then there is still a great deal of uncertainty in the actual application process. In this study, the author constructed a DIP-REM model based on computer data mining technology, which aims to provide technical support for subsequent research [15]. Among them, the author's construction of the DIP-REM prediction model for Guangdong's power resources is as follows:

$$
Q_{s}=\left[A_{1} /\left(0.03-C O_{2}\right)+B\right] *\left(t_{f}-t_{a}\right)
$$

Among them, $\mathrm{CO}_{2}$ represents the current volume fraction of carbon dioxide in the current environment; $t_{f}$ and $t_{a}$ represent the predicted output power and the original output, $A_{1}$ and $B$ represent the formula's calculation coefficients, which are 0.66 and 0.01 , respectively, and $Q_{s}$ represents power consumption.

As the author's prediction of electricity and energy, carbon dioxide emissions is an extremely important predicting factor, therefore, the author has calculated its emissions, the formula is as follows:

$$
\mathrm{CO}_{2}=\left[1-\mathrm{CO}_{2} / \mathrm{CO}_{2, t h}\right] * 56
$$

Thereinto, $\mathrm{CO}_{2}$ represents the current volume fraction of carbon dioxide in the current environment; $C \mathrm{O}_{2, t h}$ is the theoretical volume fraction.

The formula for calculating the expansion capacity of power resources is as follows:

$$
\eta_{\text {comb }}=100-Q_{s}
$$

In this formula, $Q_{s}$ represents the power consumption; $\eta_{\text {comb }}$ represents the predicted expansion of power energy.

Based on the understanding of the current economic development trend in Guangdong Province and the actual demand for energy, then the author applied the constructed DIP-REM model to the actual energy demand forecast process in Guangdong Province. In this study, the author mainly took Guangdong Province as a research case for the prediction of the demand for electric energy as a new energy source. First, the author made statistics on current energy use and distribution of 
various industries in Guangdong Province, and then the authors will report greenhouse gas emission scenarios. The use of energy resources and system planning in Guangdong Province was followed by a re-distribution of energy resources to further realize the prediction of energy demand in Guangdong Province and the optimization of its use in the later period.

\section{Result Analysis and Discussion}

\subsection{Survey Results of Energy Use Trends in China}

With the development and progress of the times, our country has gradually developed towards the process of "industrialization and urbanization". Under the new development situation, it has brought more opportunities and challenges for the development of the contemporary economy. While the rapid economic development continues to satisfy people's material and cultural needs, but also because of the extensive mode of industrial development and inappropriate industrialization process, the use of resources in China's development process has also increased, and to a certain extent, Caused a resource crisis. In the process of massive use of resources, these resources may be non-renewable resources, and the use of a large amount of resources also causes an increase in the pollution of the environment we live in. This in turn affects the sustainability of our country's national economic level. It may have a negative impact on the health of our nationals. Therefore, research on the current status of energy use and the related energy security measures have become one of the most pressing issues in China's current economic development and energy use. With the changes in the current international environment and timeliness, China has begun to realize that sustainable energy supply is an important trend in the development of China's international comprehensive level. Only in this way can China not be affected by the energy crisis, and it must To a certain extent, it provides a positive driving force for the sustainable development of China's national economy. In this study, the author made statistics on China's total energy production and consumption. The statistical results are shown in Figure 1. The results show that China's energy has been in a state where consumption is greater than production, and it also indicates to a certain extent that China needs to pay attention to the development of energy in a timely manner.

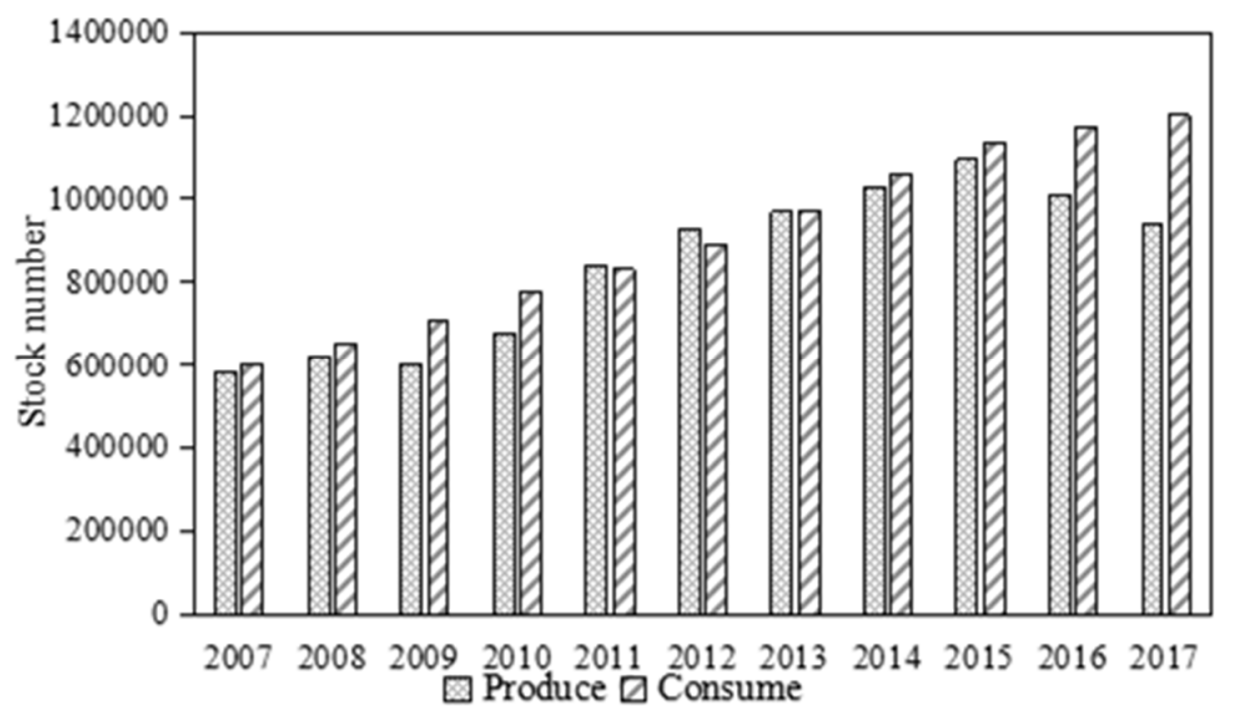

Figure 1: Survey results of energy use trends in China

\subsection{Taking Guangdong Province as an example, the results of energy production, transfer and distribution analysis}

In order to predict the energy demand of Guangdong's follow-up development, the author first investigated the energy production, transfer, and distribution of Guangdong Province. Through the reading of relevant literature and data, the authors' results of local energy production, transfer and recall of Guangdong Province during the five periods of 1997, 2002, 2007, 2012 and 2017 are shown in Table 1 and Table 2. And Table 3 shows. From the results, we can find that in the process of economic development in Guangdong Province, it may be due to the rapid development of the local economy, so that the demand for fossil fuels such as coal, oil, and natural gas is relatively large. Among the major fossil fuels, the actual use of coal may still occupy the most important position for all energy use due to limitations in its development technology, although in the early stages of development (1997 and 2002), coal consumption in Guangdong Province It is in an ascending state, but may be due to reasons such as technological transformation in some industries and the large amount of resource consumption that may be caused by the use of coal resources. So, in the modern development (2012 and 2017), Guangdong Province The use of coal resources has begun to gradually decrease; in addition, the use of coke, etc. in Guangdong Province has been steadily increasing its use throughout the development, so this may also lead to its use for such energy sources. Under the premise of a large production 
volume, we still rely on the resources from other places to meet our own development demand; From the research results, we also found that Guangdong Province's demand for certain chemical fuels for crude oil fuels is mostly transferred from overseas sources, and its local production is relatively small. This may be due to the fact that these regions are not located in the production area of crude oil. With the development of the economy of the times, the increase in the use of crude oil for a wide range of enterprises and industries (such as the transportation industry) has also led to a significant increase in the consumption of crude oil energy. Therefore, its demand for crude oil has also been increasing year by year. growth trend. However, since
Guangdong Province may have advanced crude oil refining technology, it can extract more fossil fuels (such as Table 3) from surplus products more efficiently when introducing large quantities of crude oil fuels. This, to a certain extent, also laid the foundation for the subsequent output to obtain economic benefits. The author finally wrote that Guangdong Province may have a relatively small amount of electricity due to the lack of fossil fuels. This type of energy is often introduced to other industries through the transfer of imported energy. Development needs. Therefore, in the follow-up study, the author will focus on the new type of energy source, namely the power source, to predict its energy demand.

Table 1: Local Energy Situation in Guangdong Province

\begin{tabular}{|c|c|c|c|c|c|}
\hline \multirow{2}{*}{ Resource Type } & \multicolumn{5}{|c|}{ Time } \\
\cline { 2 - 6 } & 1997 & 2002 & 2007 & 2012 & 2017 \\
\hline Natural Gas & 57.91 & 45.55 & 31.26 & 73.98 & 96.08 \\
\hline Coal & 931.21 & 1337.01 & 1384.88 & 1032.93 & 1032.93 \\
\hline Gasoline & 294.89 & 415.48 & 449.76 & 532.87 & 552.62 \\
\hline Diesel & 512.47 & 810.96 & 896.17 & 978.14 & 821.74 \\
\hline Coking coal & 172.41 & 194.97 & 211.74 & 335.27 & 387.88 \\
\hline $\begin{array}{c}\text { Liquefied } \\
\text { Petroleum Gas }\end{array}$ & 224.93 & 351.10 & 533.30 & 602.49 & 623.83 \\
\hline Fuel Oil & 38.12 & 40.62 & 40.01 & 41.56 & 39.56 \\
\hline Kerosene & 99.30 & 94.70 & 99.33 & 117.16 & 150.68 \\
\hline Oil & 585.49 & 527.96 & 418.53 & 327.76 & 327.76 \\
\hline
\end{tabular}

Table 2: Situation about Energy Importation From Outsiders in Guangdong Province

\begin{tabular}{|c|c|c|c|c|c|}
\hline \multirow{2}{*}{ Resource Type } & \multicolumn{5}{|c|}{ Time } \\
\cline { 2 - 6 } & 1997 & 2002 & 2007 & 2012 & 2017 \\
\hline Natural Gas & 21.34 & 26.99 & 32.82 & 80.79 & 150.37 \\
\hline Coal & 1074.49 & 1543.27 & 2199.86 & 2567.02 & 2700.70 \\
\hline Gasoline & 2.71 & 0.71 & 0.54 & 0.13 & 0.00 \\
\hline Diesel & 1.79 & 1.63 & 2.57 & 12.82 & 12.14 \\
\hline Coking coal & 40.47 & 133.22 & 249.78 & 350.28 & 350.28 \\
\hline $\begin{array}{c}\text { Liquefied } \\
\text { Petroleum Gas }\end{array}$ & 12.64 & 10.07 & 2.69 & 0.79 & 0.00 \\
\hline Fuel Oil & 7.91 & 10.26 & 14.44 & 20.68 & 22.26 \\
\hline Kerosene & 1.94 & 1.06 & 0.39 & 0.16 & 0.00 \\
\hline Oil & 1240.74 & 1814.58 & 202829 & 2028.29 & 2028.29 \\
\hline Electricity & 231.66 & 287.69 & 429.90 & 398.91 & 463.93 \\
\hline
\end{tabular}

Table 3: Situation about Energy Exportation in Guangdong Province

\begin{tabular}{|c|c|c|c|c|c|}
\hline \multirow{2}{*}{ Resource Type } & \multicolumn{5}{|c|}{ Time } \\
\cline { 2 - 6 } & 1997 & 2002 & 2007 & 2012 & 2017 \\
\hline Gasoline & 229.64 & 214.26 & 237.97 & 257.86 & 257.86 \\
\hline Diesel & 415.29 & 559.36 & 504.25 & 426.34 & 400.07 \\
\hline Fuel Oil & 43.58 & 18.66 & 23.68 & 20.93 & 20.93 \\
\hline Kerosene & 90.95 & 80.40 & 80.74 & 83.31 & 90.56 \\
\hline
\end{tabular}

\subsection{Taking the electricity production in Guangdong Province as an example, the results of the survey on the production value of electricity and energy for different production methods}

The author has conducted statistical data on four different forms of power generation for coal, natural gas, wind power and hydraulic power in Guangdong during the four periods of 1997, 2002, 2007, 2012 and 2017. The statistical results are shown in Figure 2. From the figure, we can see that the power production using various power generation methods has been rising year by year along with the development of the times, but we can also see that the power production method of coal, though it is the most dominant The mode of development, but its degree of increase is gradually slowing, and the increase in natural gas, wind power, and hydraulic power are significantly higher. This may be due to the fact that coal, a fossil fuel, can cause a greenhouse effect, and thus its benefits for production are not as good as those introduced to the outside, but other production methods Although it is more environmentally friendly, it is slowly rising due to technical reasons. 


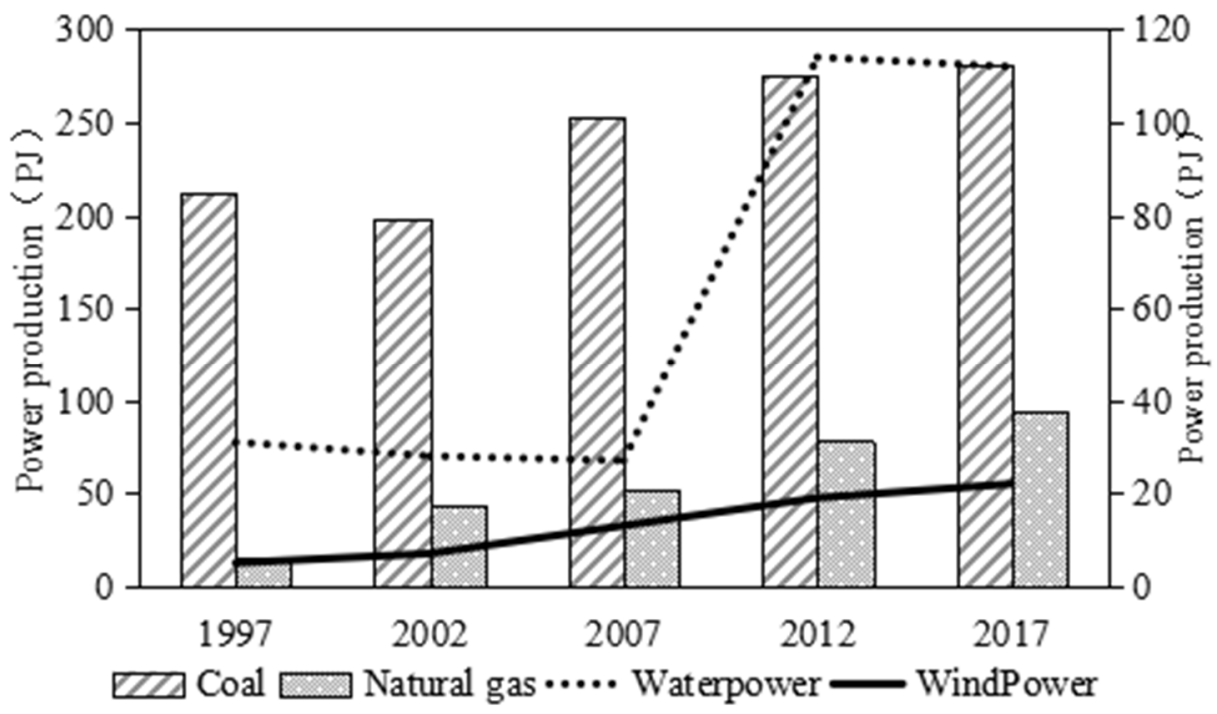

Figure 2: Statistics of four different types of power production methods

\subsection{Prediction of the Demand Trend of Power Energy in Guangdong Province Based on DIP- REM Model}

The author then used the first-round conversion of Guangdong Province's resource use according to the above statistics, and then applied the constructed DIPREM model to forecast Guangdong's electricity and energy demand trends. The forecast results are shown in Figure 3. The results show that under the same development conditions, the expansion capacity of coal, natural gas, wind power and hydraulic power generation in Guangdong Province after 10 years will be $480 \mathrm{MW}$,
$390 \mathrm{MW}, 150 \mathrm{MW}$ and $60 \mathrm{MW}$, respectively; this further shows that although coal power generation It is still the main mode of electricity production in Guangdong Province, but as the concept of renewable energy development and environmental protection deepens, its dominance is gradually declining, and natural gas has gradually become the main production method, while wind power and hydraulic power production are absolutely environmentally friendly. The method has gradually become an effective way for the production of power resources in Guangdong Province due to the improvement of production methods.

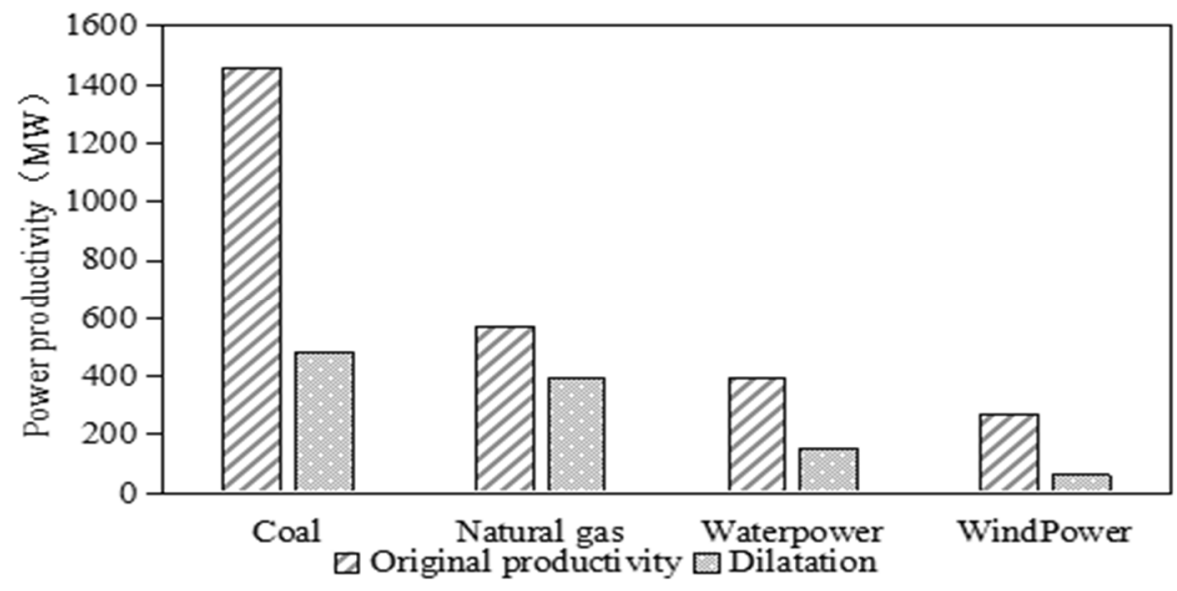

Figure 3: Forecast of Guangdong's Original Power Productivity and Demand Results

\section{Conclusion}

In the process of industrialization in today's era, the economic level of various industries in China has been greatly developed and improved. However, the rapid development of the industry has also caused a large amount of resources to be applied. Especially in recent years, China has made a large number of decisions to develop the economy while also causing a large amount of energy consumption, and due to the influence of certain political and environmental factors. The problem of deprivation has become one of the major problems that China needs to face in the course of its development. Forecasting the future development trend of energy is of great positive impetus to the efficient application of energy and the sustainable development of the entire economy. The development of computer technology also provides technical and theoretical support for the prediction of future energy development, thus making the final data analysis results more reliable. In this study, the author focused on the energy problem in Guangdong Province where the economic development of the province was relatively rapid and caused a serious 
energy problem. The author analyzed the energy use situation in Guangdong Province, and then the author took electrical energy as an example and constructed a DIP. The -REM model predicts the future development trend of Guangdong's power energy. Due to the limited theoretical level of the author, there are still many deficiencies in the study, but this study still has certain reference value for the future planning of China's energy.

\section{Acknowledgments}

This study is funded by Guangdong Provincial Colleges and Universities Characteristic Innovation ProjectStudy on the trading mechanism of enterprise energy right in Guangdong, Hong Kong and Macao Bay Area ( No.: 2020WTSCX138).

\section{Reference}

1. Urge-Vorsatz, D.; Cabeza, L.F.; Serrano, S.; Barreneche, C.; Petrichenko, K. Heating and cooling energy trends and drivers in buildings [J]. Renew. Sustain. Energy Rev. 2015, 41: 85-98.

2. Liao, S.; Yao, W.; Han, X.; Wen, J.; Cheng, S. Chronological operation simulation framework for regional power system under high penetration of renewable energy using meteorological data [J]. Appl. Energy 2017,203, 816-828.

3. Lo Basso, G.; Rosa, F.; Astiaso Garcia, D.; Cumo, F. Hybrid systems adoption for lowering historic buildings PFEC (primary fossil energy consumption)-A comparative energy analysis. Renew [J]. Energy 2018, 117, 414-433.

4. Tronchin, L.; Manfren, M.; Tagliabue, L.C. Optimization of building energy performance by means of multi-scale analysis-Lessons learned from case studies [J]. Sustain. Cities Soc. 2016, 27, 296-306.

5. Noussan, M.; Jarre, M.; Roberto, R.; Russolillo, D. Combined vs Separate Heat and Power Production-Primary Energy comparison in high renewable share contexts [J]. Appl. Energy 2018, 213, 1-10.

6. Rovense, F.; Amelio, M.; Ferraro, V.; Scornaienchi, N.M. Analysis of a concentrating solar power tower operating with a closed Joule Brayton cycle and thermal storage [J]. Int. J. Heat Technol. 2016, 34, 485-490.

7. Pisello, A.L.; Rosso, F.; Castaldo, V.L.; Piselli, C.; Fabiani, C.; Cotana, F. The role of building occupants' education in their resilience to climatechange related events [J]. Energy Build. 2017, 154, 217-231.

8. Miranda, M.T.; Montero, I.; Sepúlveda, F.J.; Arranz, J.I.; Rojas, C.V. Design and Implementation of a Data Acquisition System for Combustion Tests [J]. Energies 2017, 10, 630.
9. Barbeito, I.; Zaragoza, S.; Tarrio-Saavedra, J.; Naya, S. Assessing thermal comfort and energy efficiency in buildings by statistical quality control for autocorrelated data [J]. Appl. Energy 2017, 190, 117.

10. Manfren, M.; Aste, N.; Moshksar, R. Calibration and uncertainty analysis for computer models - A metamodel based approach for integrated building energy simulation [J]. Appl. Energy 2013, 103, 627-641.

11. Cheng, H.; Wang, X.; Zhou, M. Optimized Design and Feasibility of a Heating System with Energy Storage by Pebble Bed in a Solar Attic [J]. Energies 2017, 10, 328.

12. Turhan, C.; Simani, S.; Zajic, I.; Akkurt, G.G. Performance Analysis of Data-Driven and ModelBased Control Strategies Applied to a Thermal Unit Model [J]. Energies 2017, 10, 67.

13. Sarkar, P.; Kortela, J.; Boriouchkine, A.; Zattoni, E.; Jämsä-Jounela, S.-L. Data-Reconciliation Based Fault-Tolerant Model Predictive Control for a Biomass Boiler [J]. Energies 2017, 10, 194.

14. Glasgo, B.; Hendrickson, C.; Azevedo, I.L. Assessing the value of information in residential building simulation: Comparing simulated and actual building loads at the circuit level [J]. Appl. Energy 2017, 203, 348-363.

15. Castellani, B.; Rinaldi, S.; Bonamente, E.; Nicolini, A.; Rossi, F.; Cotana, F. Carbon and energy footprint of the hydrate-based biogas upgrading process integrated with $\mathrm{CO} 2$ valorization $[\mathrm{J}]$. Sci. Total Environ. 2018, 615, 404-411. 